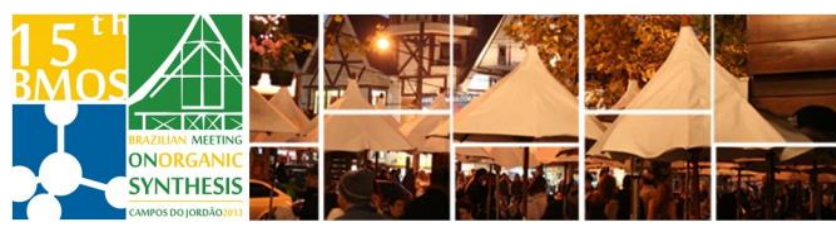

\title{
Multicomponent Combinatorial Development of Prolyl Pseudo- Peptide Catalysts: Application in the Direct Asymmetric Michael Addition
}

\author{
Alexander F. de la Torre, ${ }^{\dagger}$ Daniel G. Rivera, ${ }^{\dagger, \ddagger}$ Marco A. B. Ferreira, ${ }^{\dagger}$ Arlene G. Corrêa \\ ${ }^{\dagger}$ and Márcio W. Paixão ${ }^{\dagger}$
}

† Departamento de Química, Universidade Federal de São Carlos, São Carlos, SP, 97105-900, Brazil.

$\ddagger$ Center for Natural Products Study, Faculty of Chemistry, University of Havana, Zapata y G, 10400, La Habana, Cuba.

*e-mail corresponding author: alexanderfndzdelatorre@hotmail.com

Keywords: Organocatalysis, Michael addition, Multicomponent Reactions

\section{INTRODUCTION}

Oligopeptidic scaffolds are an important class of organocatalysts, which have found remarkable applications in a wide range of catalytic asymmetric transformations. ${ }^{1,2}$ In this way, MCRs may offer a greater promise in the field of peptide catalysis. The classic Ugi-4CR has been successful applied for the preparation of pseudo-peptidic skeletons, including $\mathrm{N}$-alkylated peptides and a wide variety of peptidomimetic by combinatorial procedures whereas, each of the four starting materials can be easily altered (Scheme 1). ${ }^{3}$ Taking into account that the MCRs have not yet been used for organocatalysts discovery, we focused our attention, ton the implementation of Ugi-4CR as a powerful tool to access new class of prolyl pseudo-peptides and therefore, apply them in asymmetric Michael reaction.

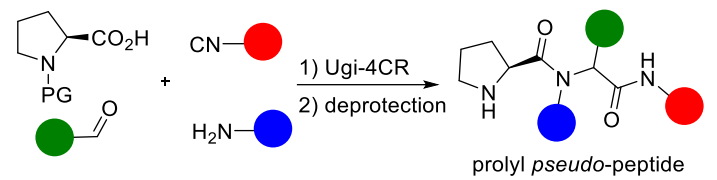

Scheme 1. Synthesis of new class of prolyl pseudo-peptides organocatalysts by Ugi-4CR

\section{RESULTS AND DISCUSSION}

A small library of Prolyl pseudo-peptides was obtained in good to excellent yields (61-93\%) by Ugi-4CR protocol. These catalysts were then tested on the directed asymmetric Michael addition (Table 1). Most pseudo-peptides catalyzed the reaction in good to excellent enantio- and diastereoselectivities, where organocatalyst 9 presented the best results in terms of stereocontrol ( $98 \%$ ee, $94: 6 \mathrm{dr}$, entry 9 ).

Lowest-energy structure of the E-enamine by a theoretical study, shows a significant shielding of the peptidic skeleton to the Re-face (Figure 1, a) which explains the high enantioselection provided by catalyst 9 and the syn predomination isomer by a SiSi attack approach (Figure 1, b)
Table 1. Screening of the enamine-catalytic performance of pseudo-peptides 1-12 in the asymmetric Michael addition

\begin{tabular}{|c|c|c|c|c|}
\hline Entry & $\mathrm{R}^{1} / \mathrm{R}^{2} / \mathrm{R}^{3}$ & $\begin{array}{l}\text { Yield } \\
(\%)^{b}\end{array}$ & syn:antic & $\begin{array}{c}\mathrm{ee} \\
(\%)^{\mathrm{d}}\end{array}$ \\
\hline 1 & Gly-OMe/H/Cy (1) & 87 & $96: 4$ & 90 \\
\hline 2 & Val-OMe/H/Cy (2) & 92 & $92: 8$ & 91 \\
\hline 3 & Leu-OMe/H/Cy (3) & 83 & $97: 3$ & 79 \\
\hline 4 & Ile-OMe/H/Cy (4) & 89 & $97: 3$ & 90 \\
\hline 5 & Phe-OMe/H/Cy (5) & 84 & $93: 7$ & 64 \\
\hline 6 & 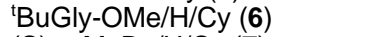 & 94 & $90: 10$ & 82 \\
\hline 7 & (S)-a-MeBn/H/Cy (7) & 74 & $96: 4$ & 89 \\
\hline 8 & $\mathrm{Bn} / \mathrm{H} / \mathrm{Cy}(8)$ & 91 & $93: 7$ & 92 \\
\hline 9 & 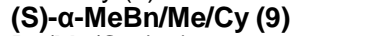 & 85 & 94:6 & 98 \\
\hline 10 & $\mathrm{Bn} / \mathrm{Me} / \mathrm{Cy}(\mathbf{1 0})$ & 84 & $94: 6$ & 87 \\
\hline 11 & (S)- $\alpha-M e B n / H / t-B u(11)$ & 93 & $94: 6$ & 91 \\
\hline 12 & (S)-a-MeBn/H/Gly-OMe (12) & 77 & $89: 11$ & 85 \\
\hline
\end{tabular}

${ }^{a}$ All reactions were conducted using 3 equiv of the aldehyde. ${ }^{b}$ Yield of isolated product as mixture of syn/anti adducts. 'Determined by ${ }^{1} \mathrm{H}$-NMR spectroscopy and HPLC analysis. ${ }^{d}$ Determined by chiralphase HPLC analysis on the major diastereomer.

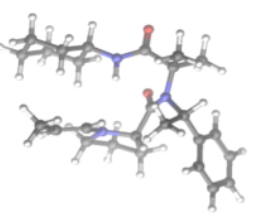

a)

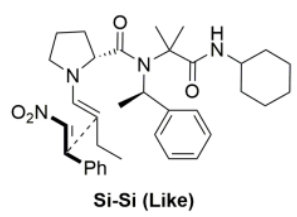

b)
Figure 1. a) Lowest-energy structure of the anti enamine derived from catalyst 9 at M06-2X/6-31+G(d,p)//M06-2X/6-31G(d) [SDM, toluene] level. b) Si-Si attack approach of enamine.

\section{CONCLUSION}

We have demonstrated the Ugi-4CR-based generation of a new prolyl pseudo-peptides combinatorial library and the screening of their catalytic efficacy in the asymmetric conjugate addition of aldehydes to nitroolefins in excellent stereocontrol.

\section{ACKNOWLEDGEMENTS}

FAPESP, CNPq and CAPES for financial support.

\section{REFERENCES}

E. A. Colby Davie, S. M. Mennen, Y. Xu, S. J. Miller, Chem. Rev. 2007, 107, 5759-5812.

2 Revell, J. D.; Wennemers, H. Curr. Opin. Chem. Biol. 2007, 11, 269-278.

${ }^{3}$ A. Dömling, W. Wang, K. Wang, Chem. Rev. 2012, 112, 3083-3135. 